\title{
NKG2D ligands in tumor immunity: two sides of a coin
}

\author{
Jinyu Zhang ${ }^{1+}$, Fahmin Basher ${ }^{1 \dagger}$ and Jennifer D. Wu ${ }^{1,2 *}$ \\ 1 Department of Microbiology and Immunology, Medical University of South Carolina, Charleston, SC, USA \\ ${ }^{2}$ Cancer Immunology Program, Hollings Cancer Center, Charleston, SC, USA
}

\section{Edited by:}

Anahid Jewett, UCLA School of

Dentistry and Medicine, USA

\section{Reviewed by:}

Graham Robert Leggatt, University of

Queensland, Australia

Janko Kos, University of Ljubljana,

Slovenia

Yasmina Laouar, University of

Michigan, USA

Nicholas Cacalano, University of

California at Los Angeles, USA

\section{*Correspondence:}

Jennifer D. Wu, Department of

Microbiology and Immunology,

Medical University of South Carolina,

Charleston, SC 29425, USA

e-mail:wujjd@musc.edu

${ }^{\dagger}$ Jinyu Zhang and Fahmin Basher

have contributed equally to this work.
The activating/co-stimulatory receptor NKG2D (natural-killer group 2, member D) is expressed on the surface of all human NK, NKT, CD8 ${ }^{+} \mathrm{T}$, and subsets of $\gamma \delta^{+} \mathrm{T}$ cells. The significance of NKG2D function in tumor immunity has been well demonstrated in experimental animal models. However, the role of human NKG2D ligands in regulating tumor immunity and cancer prognosis had been controversial in the literature. In this review, we summarize the latest advancement, discuss the controversies, and present evidence that membrane-bound and soluble NKG2D ligands oppositely regulate tumor immunity. We also discuss new perspectives of targeting NKG2D ligands for cancer immunotherapy.

Keywords: NKG2D ligands, cancer, NK cells, T cells, tumor immunity

\section{INTRODUCTION}

The discovery of the natural killer (NK) cell activating receptor NKG2D and its ligand MHC I chain-related molecule (MIC) expression on human cancer cells marks one of the most significant milestones in understanding NK cells in cancer immune surveillance in the last several decades (1-4). NKG2D, initially identified on NK cells, was also found to be expressed by CD8 $\mathrm{T}$ cells (only activated CD8 T cells in mouse), NKT cells, and subsets of $\gamma \delta \mathrm{T}$ cells (4-6). In vitro studies have demonstrated that ligation of NKG2D by its ligands provides activating signal to NK cells and co-stimulatory signal to $\mathrm{T}$ cells $(5,7,8)$. In vivo studies with experimental animals have demonstrated that ectopic expression of NKG2D ligands on tumor cells is sufficient to cause tumor rejection $(9,10)$. These data suggested that sustaining or increasing NKG2D expression on tumor cells should be a viable avenue for developing effective cancer immunotherapy. However, human cancer cells are found to broadly express NKG2D ligands and yet progress $(1,11)$. Moreover, clinical studies with different cancer types and even different disease stages within the same type of cancer presented conflicting prognostic values of NKG2D ligands $(12-15)$. The conundrum and controversy have withheld the further exploration of NKG2D ligand-mediated cancer immunotherapy. In this review, we will analyze controversial clinical studies and consolidates the discrepancy in the literature. We will present most updated evidence that different physical forms of NKG2D ligands could oppositely regulate tumor immunity. We also propose therapeutic perspectives and options for exploiting NKG2D ligands-based cancer immunotherapy. Finally, we will also introduce a newly developed pre-clinical "humanized" mouse model for validating immunotherapies to target NKG2D ligands.

\section{NKG2D, AN ACTIVATING IMMUNE RECEPTOR}

Natural-killer group 2, member D, also known as Klrk1 (NKG2D), a C-type lectin-like receptor, was firstly identified in natural killer (NK) as an activating immune receptor (16). In human, NKG2D is not only expressed by all NK cells $(17,18)$, but is also expressed by all CD8 $8^{+} \mathrm{T}$ cells, and subsets of $\gamma \delta^{+} \mathrm{T}$ cells as a co-stimulatory receptor $(2,6,8,19)$. In mice, NKG2D is also expressed by all NK cells, however, only by activated $\mathrm{CD} 8^{+} \mathrm{T}$ cells and approximately $25 \%$ of spleen $\gamma \delta^{+} \mathrm{T}$ cells (7). NKG2D is also expressed by activated mouse macrophage (7). NKG2D is rarely expressed by mouse intestinal intraepithelial $\gamma \delta^{+} \mathrm{T}$ cells (20). Little or no $\mathrm{CD}^{+} \mathrm{T}$ cells naturally express NKG2D in both human and mouse. Notably, NKG2D is not only expressed in mice and humans but also expressed in other mammals $(21,22)$.

NKG2D is a type II transmembrane glycoprotein, which does not contain any known signaling elements in the intracellular domain (23). Resembling many activating receptors, NKG2D depends on an adaptor molecule to initiate signaling transduction and cellular activation. Two adaptor molecules, DNAX-activating proteins of $10 \mathrm{kDa}(\mathrm{DAP} 10)$ and $12 \mathrm{kDa}$ (DAP12), were identified to associate with NKG2D. The selection of adaptor molecule association depends on the cell types and the isoforms of NKG2D. In resting mouse NK cells, NKG2D exclusively associates with DAP10; whereas in activated NK cells, NKG2D associates with DAP10 and DAP12 $(24,25)$. In both human and activated mouse $\mathrm{T}$ cells, NKG2D exclusively associates with DAP10, presumably due to CD8 T cells lacking DAP12 expression (20,23). In mice, alternative splicing generates two NKG2D isoforms, NKG2D long (NKG2DL) and the alternatively spliced NKG2D short (NKG2D-S) which is 13 amino acid shorter in the cytoplasmic N-terminus than 
NKG2D-L (25). Initial study with primary mouse NK cells demonstrated that NKG2D-S associated with DAP10 or DAP12, whereas NKG2D-L exclusively associated with DAP10 (25). A more recent study found that DAP10 and DAP12 competed equally for binding NKG2D variants when co-expressed in CD8 T cells (26). These findings suggested that NKG2D signaling could be more complicated than our current understandings. Similarly, the isoform NKG2D-s was found initially only in activated mouse NK cells and later was also described in naïve mouse NK cells (25). Whether activated human NK cells and macrophages also express NKG2D is controversial to date due to discrepancies in different experimental settings by different investigators $(27,28)$. DAP 10 and DAP12 association activates different signaling pathways (Figure 1). The DAP10 molecule contains an YXXM tyrosine-based motif (23) that recruits the p85 subunit of phosphoinositide kinase-3 (PI3K) and growth factor receptor-bound protein 2 (Grb2). This signaling cascade is similar to which delivered by the T cell co-stimulatory molecules CD28 and ICOS (29, 30). The DAP12 molecule contains an ITAM, which recruits ZAP70 and Syk to mediate NK cell activation (25). The selection of adaptor molecule and the ensuing activation of different signaling pathways may explain the functional differences of NKG2D in NK cells and T cells. Binding of NKG2D to its ligands is sufficient to induce NK cell activation, even with inhibitory signals, such as MHC molecules (31), but only co-stimulates CD8 T cells or $\gamma \delta$ T cells $(8,32)$.

NKG2D expression and signaling can be regulated by cytokines and tumor-derived factors. Cytokines, such as IL-2, IL-7, IL-12, IL-15, and type I interferons (IFNs) increase cell surface expression of NKG2D (33). IL-15 signaling not only regulates NKG2D expression but also increases the expression of DAP10 and phosphorylates the adaptor molecule to prime NKG2D signaling (34). On the contrary, cytokines such as IL- 21, IFN- $\gamma$, and TGF- $\beta$ have been shown to decrease NKG2D expression. IL-21 has been reported to reduce expressions of DAP10 and NKG2D in human $\mathrm{CD}^{+} \mathrm{T}$ cells and NK cells (35). In mice, IL-21 stimulation of NK cells is dependent on regulating the NKG2D expression in mouse model of breast carcinoma (36). TGF- $\beta$ has been shown to downregulate NKG2D expression; however, the effect can be reversed by IL- 2 or IL-18 (37).

\section{REGULATION OF NKG2D LIGANDS}

NKG2D ligands are structural homologs of MHC class I molecules. NKG2D ligands are absent or rarely expressed in normal tissues, but are extensively expressed in various malignancies and viral-infected tissues $(8,11)$. The identified human NKG2D ligands include class-I-related chains-related molecules $\mathrm{A}$ and $\mathrm{B}$ (MICA and MICB) proteins and retinoic acid early transcripts1 (RAET1), also known as UL-16 binding proteins (38). To date, identified mouse NKG2D ligands include five different RAET1 isoforms (RAET1 $\alpha$, RAET1 $\beta$, RAET1 $\gamma, \operatorname{RAET} 1 \delta$, and RAET $1 \varepsilon$ ), three different $\mathrm{H} 60$ isoforms (H60a, b, and c), and one MULT1 gene $(39,40)$ (Figure 2). No MIC homologs have been identified in rodents. Although NKG2D ligands are structural homologs of MHC class I molecules, they do not present antigen to $\mathrm{T}$ cells or bind $\beta 2$-microglobulin (1).

NKG2D ligands are prevalently expressed in human malignancies. MIC and ULBP families of ligands are found prevalently expressed by carcinomas of the breast, lung, colon, ovary, kidney, and prostate, melanomas, gliomas, and leukemia (2, 11, 12, 4143). Certain normal human tissues such as gastric and bronchial epithelia were found to express NKG2D ligand MIC (44). Given that NKG2D ligand expression can be induced by stress and that gastric and bronchial mucosal epithelia are frequently exposed to microbial organisms (1), these observations are anticipated.

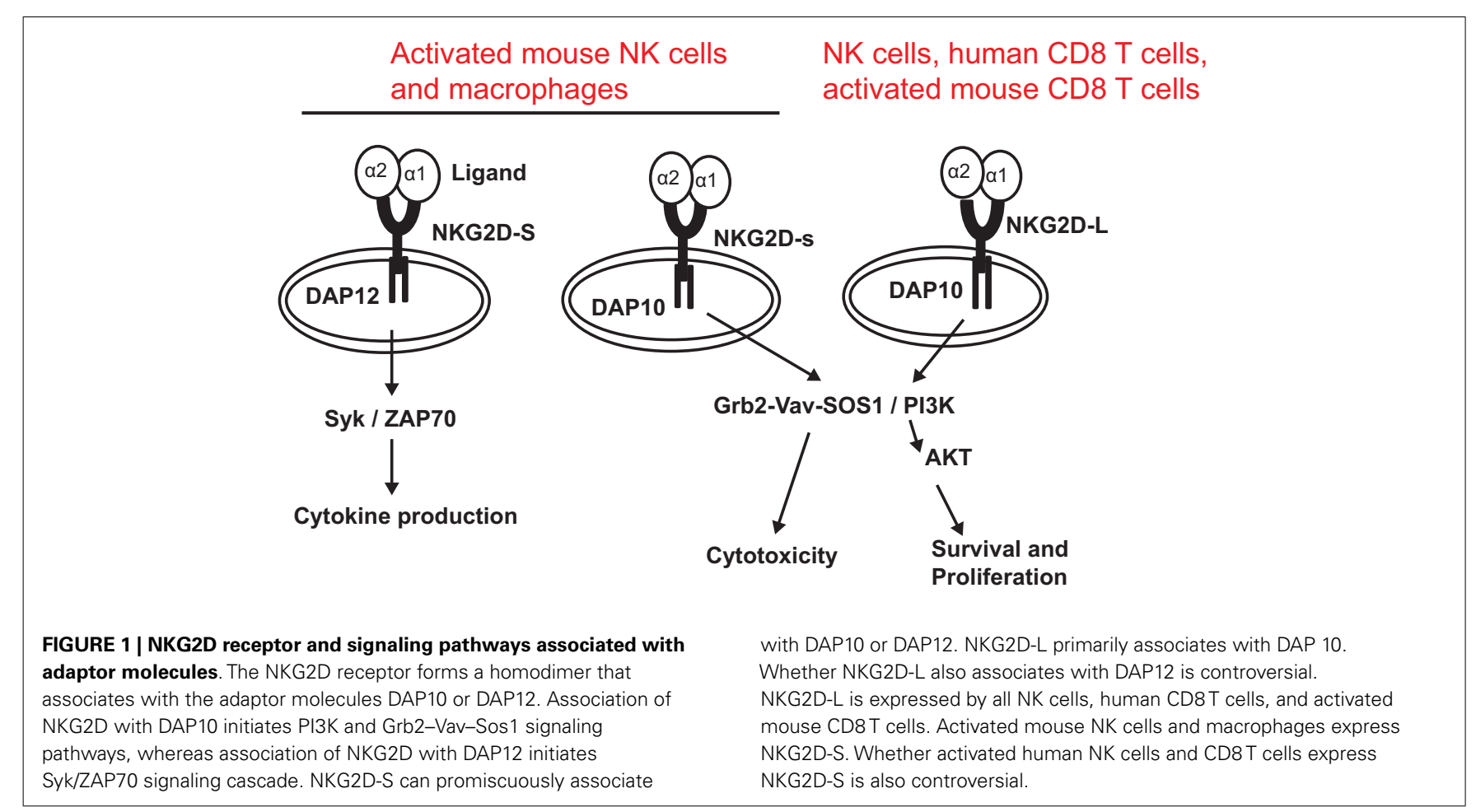




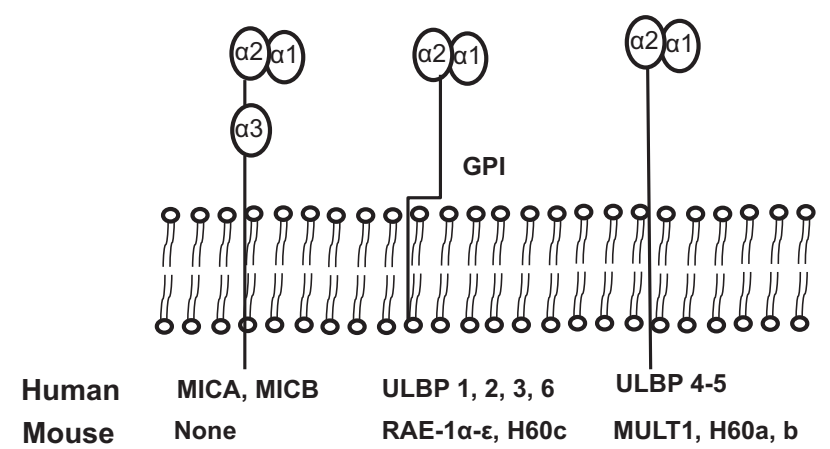

FIGURE 2 | Schematic illustration of identified ligands for human and mouse NKG2D. The unique human NKG2D ligands MICA and MICB have $\alpha 1, \alpha 2$, and $\alpha 3$ extracellular domains and transmembrane domains, sharing structural homology with $\mathrm{MHCl}$. All other human NKG2D ligands and all mouse NKG2D ligands lack the $\alpha 3$ domain. Murine NKG2D ligands, RAE1 $\alpha-\varepsilon$ and $\mathrm{H} 60 \mathrm{c}$, and human ULBP1-6 are glycosylphosphatidylinositol (GPI)-linked to the membrane. Human ligands, ULBP4 and ULBP5, and mouse ligands, MULT1, and $\mathrm{H} 60 \mathrm{a}$ and $\mathrm{H} 60 \mathrm{~b}$, are transmembrane proteins

The gut epithelium constitutively expresses MICA; however, the expression can be altered with changes in the gut flora in inflammatory states such as Crohn's disease and celiac disease $(45,46)$. Of note, NKG2D ligands are also found to be upregulated in activated T cells of both human and mouse origin $(47,48)$. Collectively, these studies suggest that NKG2D ligand expression in tissues is regulated by the pathogenic physiological environment to adequately differentiate between healthy and potential target cells.

Regulation of NKG2D ligand exerts at different levels, including transcription, mRNA stability, translation, protein stabilization, and excretion/shedding of ligands from cells (40, 49-51). DNA damage response induces the transcription of an array of NKG2D ligands, such as ULBP1 and ULBP2 and MIC family molecules (52). Regulation of NKG2D ligands in response to DNA damage depends on the accumulation of cytosolic DNA and the induction of nucleotide sensing pathways, which activate the TANK-binding kinase 1 and the IFN regulatory factor 3 (53). In addition, MICA, $M I C B$, and $U L B P 3$ transcripts have been reported to be targeted by endogenous microRNAs (54). Inhibition of PI3K impaired Raet1 transcript levels, and was further observed at the protein level suggesting that $\mathrm{PI} 3 \mathrm{~K}$ regulates Raet 1 at the transcriptional and post-transcriptional stage (55). In addition to its role in transcriptional regulation of MICA and MICB (56), heat shock counteracts ubiquitin-mediated degradation of MULT1 (57). At the post-translational level, NKG2D ligands such MICA, MICB, and ULBPs were found to be cleaved from the cell surface by proteases ADAM10/17 and MMP14 and in some cases by tumorderived exosomes (58-62). Notably, expression of NKG2D ligands was also shown to be downregulated by cytokines such as IFN$\gamma$, IFN- $\alpha$, transforming growth factor- $\beta$, and IL-10, although the underlying mechanisms have not been elucidated extensively (63).

\section{TWO FACES OF NKG2D LIGANDS IN REGULATING TUMOR IMMUNITY}

Although induction of NKG2D ligand expression is associated with oncogenesis, expression of NKG2D ligands does not favor progression to carcinoma. In fact, multiple lines of evidence conclusively demonstrated that NKG2D ligand-induced receptor activation plays a significant role in tumor immune surveillance. Ectopic expression of NKG2D ligands on diverse tumor cell lines resulted in tumor rejection in experimental animal models through activation of NK cells and in some cases CD8 $\mathrm{T}$ cells $(7,9,10,52)$. To support the significance of ligandengaged NKG2D function in tumor inhibition, an elegant study by Smyth et al. demonstrated that antibody neutralizing NKG2D increased the incidence of MCA-induced sarcoma formation (64). Furthermore, Guerra et al. using a genetic approach showed that NKG2D-deficient transgenic adenocarcinoma of the mouse prostate (TRAMP) developed three times more aggressive tumors than NKG2D-intact TRAMP littermates (65). Together, these studies in experimental animal models demonstrated that immunity mediated by ligand-NKG2D interaction plays a significant role in controlling tumor initiation and tumor progression.

In contrast to the conclusive data from animal models, clinical data eliciting the significance of NKG2D ligands in tumor immunity are rather controversial and presented discrepancies in conclusion. In early stages of breast and colorectal cancer, levels of tissue MIC expression were shown to positively correlate with improved survival $(12,15)$. In invasive breast and ovarian cancer, levels of tissue MIC expression were shown to correlate with poor prognoses $(13,14)$. These conflicting clinical observations are most likely resulted from discrepancies on how the ligand expression is assayed. Human cancer cells have broadly adapted a proteases or exosome-mediated strategy to shed surface NKG2D ligands (51). It has been proposed that membrane-bound NKG2D ligands stimulate immunity whereas soluble NKG2D ligands impair host immunity. The concept that membrane-bound and soluble forms of NKG2D ligands oppositely regulate tumor immunity was recently demonstrated by two elegant lines of "humanized" transgenic animals. Liu et al. created two lines of transgenic animals that express native human MICB and engineered shedding-resistant mutant MICB (MICB.A2) specifically in the mouse prostate under the control of prostate-specific promoter. These two lines of transgenic animals have no differences phenotypically. However, when they were crossed with the TRAMP mice that develop spontaneous prostate tumors, TRAMP/MICB mice exhibited expedited tumor progression in comparison to TRAMP littermates whereas TRAMP/MICB.A2 mice enjoyed tumor-free survival (66). Liu et al. further demonstrated that the tumor progression in TRAMP/MICB mice was due to elevated serum sMIC and severe impaired of host immunity, exemplified by depletion of peripheral NK cell populations. This study provided the first and strongest in vivo evidence that membrane-bound NKG2D ligands and soluble NKG2D ligands play opposite roles in tumor immunity. Given that tumor cells express more proteases as disease progression and that elevated levels of serum sMIC correlates with invasive malignancies in many types of cancers $(66,67-71)$, the conundrum of different clinical observation may not be "conflicting" after all if the assay can distinguish tissue levels of sMIC versus membrane-bound MIC.

Soluble NKG2D ligands suppress tumor immunity via multiple mechanisms. Downregulation of NKG2D expression on effector cells by soluble NKG2D ligands is the most common mechanism 
described thus far $(2,7,9,10,64-66)$. Hanaoka et al. described that sMIC can also induce loss of the $\mathrm{CD} 3 \zeta$ signaling adaptor, which occurs in T cells and NK cells in cancer patients, after NKG2D signaling leads to Fas-mediated caspases $3 / 7$ activation and cleavage of CD3 $\zeta$ (72), leading to T cell and NK cell dysfunction. Liu et al. have recently described that sMIC impairs the ability of NK cells to self-renew in tumor host and thus perturbs NK cell homeostasis (66). Given that NK cells play a significant role in shaping adaptive immunity by providing IFN $\gamma$ and priming dendritic cells, the magnitude of negative imprints of sMIC on tumor immunity may be larger than we have understood. Nonetheless, these studies imply the critical role of NKG2D ligands in regulating tumor immunity although the mechanism may be a complex.

\section{TARGETING NKG2D LIGANDS FOR CANCER IMMUNITY}

The significance of NKG2D-mediated immunity in controlling tumor development and progression has been well demonstrated. It is also evident that different membrane-bound and soluble NKG2D ligands oppositely regulate NKG2D-mediated tumor immunity. Based on these understandings, cancer therapeutic interventions should be focused on at least the following aspects: (a) sustain and enhance NKG2D expression and signaling on effector cells; (b) sustain and enhance the level of membrane-bound NKG2D ligand on tumor cells; (c) eliminate soluble NKG2D ligands.
Tumor-derived sMIC has been shown to not only downregulate NKG2D expression on effector cells but also to perturb NK cell peripheral maintenance. One candidate strategy to overcome or reduce the negative effect of sMIC on effector cells is through intervention of IL-15 agonists. As a member of the gamma cytokine family, IL-15 can not only increase NKG2D expression (10, 7375) but also cross-prime NKG2D signaling pathways (34). We have shown that IL-15 can restore and further augment NKG2D expression on NK cells isolated from cancer patients that have lost surface NKG2D expression $(76,77)$. Moreover, IL-15 has been shown to be important for NK cell homeostatic maintenance (78, 79) (Figure 3A). With IL-15 or its agonist currently in clinical trial, this therapy alone or in combination with strategies targeting sMIC is soundly plausible.

With the understanding of how shedding of MIC is regulated in tumor cells $(49,51)$, several therapeutic targets may be considered. Proteases, such as ADAM (a disintegrin and metalloproteinase)-10, ADAM-17 (60), and MMP-14 have been found to directly contribute to MIC shedding through proteolytic activities $(62,80)$. The thiol isomerase ERp5 has been shown to regulate MIC shedding by reducing the disulfide bond of MIC to induce conformational changes and thus allow the access of proteolytic enzymes (81). Theoretically, ERp5 and the MIC-shedding-contributing proteases should be considered as therapeutic targets. However, given the broad and constitutive
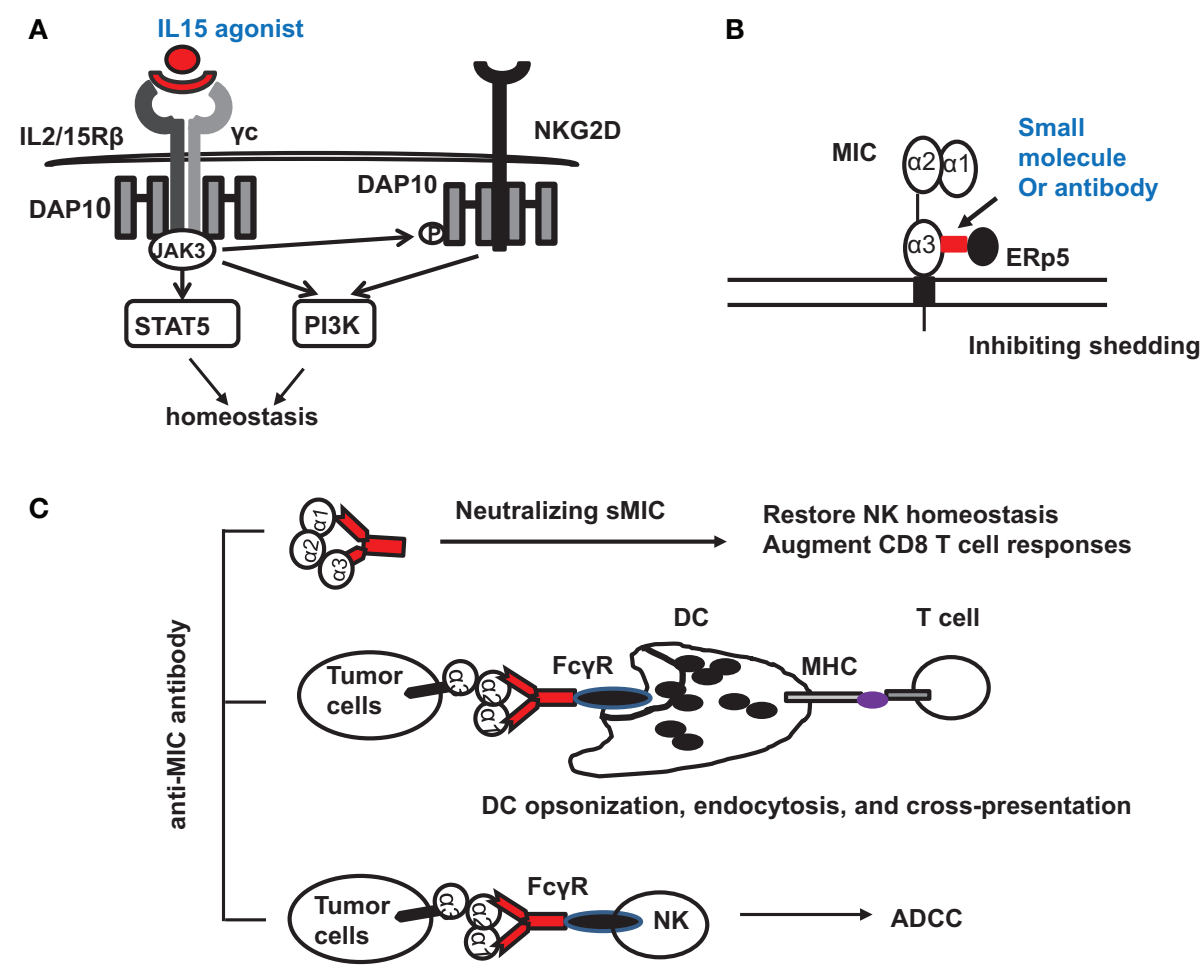

FIGURE 3 | Potential therapeutic interventions to target NKG2D ligand MIC for cancer immunotherapies. (A) Counteracting the negative effect of soluble MIC on the receptor and NK cells with IL-15 agonists. Signaling initiated by IL-15 agonists not only results in JAK3-mediated activation of STAT5 and PI3K pathways to support NK cell proliferation and survival but also phosphorylates the adaptor DAP10 to prime NKG2D signaling. (B) Antibody or small molecule to block the interaction of MIC with ERp5 and thus inhibits MIC shedding. (C) Therapy with MIC specific antibody to: (i) neutralize serum sMIC and thus revive NK cell homeostasis and augment CD8 T cell function; (ii) opsonize tumor cells to enhance DC endocytosis through $\mathrm{Fc}$ receptor and cross-presentation of tumor antigen to effectorT cells; (iii) induce antibody-dependent cytotoxicity of NK cells. 
function of these molecules in normal cellular physiology, therapeutic targeting could be challenging to avoid systemic toxicity. However, a highly conserved six-amino acid (6-aa) motif in the $\alpha 3$ domain of MIC has been identified to regulate the interaction of MIC with ERp5 and thus the shedding of MIC (82). Mutation of the six-amino acid motif completely prevented MIC shedding and enhanced tumor cell susceptibility to NK cell killing (82). Given the restricted expression of MIC, targeting the MIC-shedding regulatory motif may be more feasible for therapeutic intervention to sustain tumor cell surface MIC expression (Figure 3B).

One of the promising strategies to overcome immune suppressive effect of sNKG2D ligands is neutralizing antibody (Figure 3C). The idea is supported by clinical observations demonstrating that patients who developed anti-MIC autoantibody had reduced serum sMIC and better prognosis (83). In a clinical trial of melanoma patients with anti-CTLA-4 antibody blockade vaccine with autologous tumor cells engineered to express GM-CSF, it was shown that patients with high level of anti-MICA autoantibody presented better response to therapy (84). At least three mechanisms could contribute to the enhanced therapeutic responses. The first would be the evident reduction of serum sMIC to eliminate its immune suppressive effect. The second is through antibody opsonizing antigen presenting DC cells to enhance crosspresentation of tumor cells that express membrane-bound MIC $(84,85)$. The third may be through antibody-mediated ADCC effect to enhance NK cell killing of tumor cells that express membrane-bound MIC.

As a final reminder, the efficacy of targeting MIC-shedding motif or of an antibody directly targeting sMIC as novel intervention for cancer immunotherapy needs to be validated in preclinical models before moving to clinical trials. Due to the limitation that no human MIC homology is identified in rodents and that tumor shedding of MIC is only described in cancer patients, no clinically relevant animal model has been available to validate these therapeutic interventions until the recently described TRAMP/MIC double transgenic mouse model (66). Liu et al. described that the TRAMP/MIC mice closely resemble a broad spectrum of $\mathrm{MIC}^{+}$cancer patients in the dynamic interaction of MIC-shedding and cancer progression. This model should provide a very useful tool for pre-clinical validation of targeting NKG2D ligand MIC for cancer immunotherapy.

\section{CONCLUSION}

In summary, it is evident that NKG2D-mediated immunity is significant in potentiating anti-tumor responses. The exploitation of the NKG2D/NKG2D ligands pathway could be a promising strategy for anti-tumor immune therapy. However, NKG2D ligands present two contradictory faces in regulating NKG2D-mediated anti-tumor immunity. Membrane-bound NKG2D ligands stimulate anti-tumor immunity whereas soluble ligands suppress antitumor immunity. Based on these understandings, interventions for cancer immunotherapy should aim at enhancing NKG2D expression and signaling in effector cells, sustaining the highest levels of NKG2D ligands on tumor cell surface, and eliminating soluble NKG2D ligands. The recently developed "humanized" TRAMP/MIC mice should serve as a powerful tool for validating various targeting strategies for $\mathrm{MIC}^{+}$malignancies, which represents the majority of human cancers.

\section{ACKNOWLEDGMENTS}

We thank John Jaren for critical reading of the manuscript. JW and her laboratory were funded by NIH grant 1R01CA149405 and A. David Mazzone - Prostate Cancer Foundation Challenge Award.

\section{REFERENCES}

1. Groh V, Bahram S, Bauer S, Herman A, Beauchamp M, Spies T. Cell stressregulated human major histocompatibility complex class I gene expressed in gastrointestinal epithelium. Proc Natl Acad Sci U S A (1996) 93:12445-50. doi:10.1073/pnas.93.22.12445

2. Groh V, Rhinehart R, Secrist H, Bauer S, Grabstein KH, Spies T. Broad tumor-associated expression and recognition by tumor-derived gamma delta T cells of MICA and MICB. Proc Natl Acad Sci U S A (1999) 96:6879-84. doi:10.1073/pnas.96.12.6879

3. Long EO. Tumor cell recognition by natural killer cells. Semin Cancer Biol (2002) 12:57-61. doi:10.1006/scbi.2001.0398

4. Raulet DH. Roles of the NKG2D immunoreceptor and its ligands. Nat Rev Immunol (2003) 3:781-90. doi:10.1038/nri1199

5. Bauer S, Groh V, Wu J, Steinle A, Phillips JH, Lanier LL, et al. Activation of NK cells and T cells by NKG2D, a receptor for stress-inducible MICA. Science (1999) 285:727-9. doi:10.1126/science.285.5428.727

6. Vivier E, Tomasello E, Paul P. Lymphocyte activation via NKG2D: towards a new paradigm in immune recognition? Curr Opin Immunol (2002) 14:306-11. doi:10.1016/S0952-7915(02)00337-0

7. Diefenbach A, Jamieson AM, Liu SD, Shastri N, Raulet DH. Ligands for the murine NKG2D receptor: expression by tumor cells and activation of NK cells and macrophages. Nat Immunol (2000) 1:119-26. doi:10.1038/77793

8. Groh V, Rhinehart R, Randolph-Habecker J, Topp MS, Riddell SR, Spies T. Costimulation of CD8alphabeta T cells by NKG2D via engagement by MIC induced on virus-infected cells. Nat Immunol (2001) 2:255-60. doi:10.1038/85321

9. Cerwenka A, Baron JL, Lanier LL. Ectopic expression of retinoic acid early inducible-1 gene (RAE-1) permits natural killer cell-mediated rejection of a MHC class I-bearing tumor in vivo. Proc Natl Acad Sci U S A (2001) 98:11521-6. doi:10.1073/pnas.201238598

10. Diefenbach A, Jensen ER, Jamieson AM, Raulet DH. Rael and H60 ligands of the NKG2D receptor stimulate tumour immunity. Nature (2001) 413:165-71. doi:10.1038/35093109

11. Pende D, Rivera P, Marcenaro S, Chang CC, Biassoni R, Conte R, et al. Major histocompatibility complex class I-related chain A and UL16-binding protein expression on tumor cell lines of different histotypes: analysis of tumor susceptibility to NKG2D-dependent natural killer cell cytotoxicity. Cancer Res (2002) 62:6178-86.

12. Watson NF, Spendlove I, Madjd Z, McGilvray R, Green AR, Ellis IO, et al. Expression of the stress-related MHC class I chain-related protein MICA is an indicator of good prognosis in colorectal cancer patients. Int J Cancer (2006) 118:1445-52. doi:10.1002/ijc. 21510

13. Madjd Z, Spendlove I, Moss R, Bevin S, Pinder SE, Watson NF, et al. Upregulation of MICA on high-grade invasive operable breast carcinoma. Cancer Immun (2007) 7:17.

14. McGilvray RW, Eagle RA, Rolland P, Jafferji I, Trowsdale J, Durrant LG. ULBP2 and RAET1E NKG2D ligands are independent predictors of poor prognosis in ovarian cancer patients. Int J Cancer (2010) 127:1412-20. doi:10.1002/ijc.25156

15. De Kruijf EM, Sajet A, Van Nes JG, Putter H, Smit VT, Eagle RA, et al. NKG2D ligand tumor expression and association with clinical outcome in early breast cancer patients: an observational study. BMC Cancer (2012) 12:24. doi:10.1186/1471-2407-12-24

16. Yabe T, McSherry C, Bach FH, Fisch P, Schall RP, Sondel PM, et al. A multigene family on human chromosome 12 encodes natural killer-cell lectins. Immunogenetics (1993) 37:455-60. doi:10.1007/BF00222470

17. Houchins JP, Yabe T, McSherry C, Miyokawa N, Bach FH. Isolation and characterization of NK cell or NK/T cell-specific cDNA clones. J Mol Cell Immunol (1990) 4:295-304; discussion 305-296.

18. Houchins JP, Yabe T, McSherry C, Bach FH. DNA sequence analysis of NKG2, a family of related cDNA clones encoding type II integral membrane proteins 
on human natural killer cells. J Exp Med (1991) 173:1017-20. doi:10.1084/jem. 173.4.1017

19. Wang H, Yang D, Xu W, Wang Y, Ruan Z, Zhao T, et al. Tumor-derived soluble MICs impair CD3(+)CD56(+) NKT-like cell cytotoxicity in cancer patients. Immunol Lett (2008) 120:65-71. doi:10.1016/j.imlet.2008.07.001

20. Jamieson AM, Diefenbach A, McMahon CW, Xiong N, Carlyle JR, Raulet DH. The role of the NKG2D immunoreceptor in immune cell activation and natural killing. Immunity (2002) 17:19-29. doi:10.1016/S1074-7613(02)00333-3

21. Yim D, Jie HB, Sotiriadis J, Kim YS, Kim KS, Rothschild MF, et al. Molecular cloning and characterization of pig immunoreceptor DAP10 and NKG2D. Immunogenetics (2001) 53:243-9. doi:10.1007/s002510100321

22. Savithri B, Khar A. A transmembrane-anchored rat RAE-1-like transcript as a ligand for NKR-P2, the rat ortholog of human and mouse NKG2D. Eur J Immunol (2006) 36:107-17. doi:10.1002/eji.200535350

23. Wu J, Song Y, Bakker AB, Bauer S, Spies T, Lanier LL, et al. An activating immunoreceptor complex formed by NKG2D and DAP10. Science (1999) 285:730-2. doi:10.1126/science.285.5428.730

24. Lanier LL, Corliss BC, Wu J, Leong C, Phillips JH. Immunoreceptor DAP12 bearing a tyrosine-based activation motif is involved in activating NK cells. Nature (1998) 391:703-7. doi:10.1038/35642

25. Diefenbach A, Tomasello E, Lucas M, Jamieson AM, Hsia JK, Vivier E, et al. Selective associations with signaling proteins determine stimulatory versus costimulatory activity of NKG2D. Nat Immunol (2002) 3:1142-9. doi:10.1038/ni858

26. Rabinovich B, Li J, Wolfson M, Lawrence W, Beers C, Chalupny J, et al. NKG2D splice variants: a reexamination of adaptor molecule associations. Immunogenetics (2006) 58:81-8. doi:10.1007/s00251-005-0078-x

27. Karimi M, Cao TM, Baker JA, Verneris MR, Soares L, Negrin RS. Silencing human NKG2D, DAP10, and DAP12 reduces cytotoxicity of activated CD8+ T cells and NK cells. J Immunol (2005) 175:7819-28. doi:10.4049/jimmunol.175.12.7819

28. Basu S, Eriksson M, Pioli PA, Conejo-Garcia J, Mselle TF, Yamamoto S, et al. Human uterine NK cells interact with uterine macrophages via NKG2D upon stimulation with PAMPs. Am J Reprod Immunol (2009) 61:52-61. doi:10.1111/ j.1600-0897.2008.00661.x

29. Boise LH, Minn AJ, Noel PJ, June CH, Accavitti MA, Lindsten T, et al. CD28 costimulation can promote $\mathrm{T}$ cell survival by enhancing the expression of Bcl-XL. Immunity (1995) 3:87-98. doi:10.1016/1074-7613(95)90161-2

30. Wallin JJ, Liang L, Bakardjiev A, Sha WC. Enhancement of CD8+ T cell responses by ICOS/B7h costimulation. J Immunol (2001) 167:132-9. doi:10. 4049/jimmunol.167.1.132

31. Kim S, Poursine-Laurent J, Truscott SM, Lybarger L, Song YJ, Yang L, et al. Licensing of natural killer cells by host major histocompatibility complex class I molecules. Nature (2005) 436:709-13. doi:10.1038/nature03847

32. Wu J, Groh V, Spies T. T cell antigen receptor engagement and specificity in the recognition of stress-inducible MHC class I-related chains by human epithelial gamma delta T cells. J Immunol (2002) 169:1236-40. doi:10.4049/jimmunol. 169.3.1236

33. Marcais A, Viel S, Grau M, Henry T, Marvel J, Walzer T. Regulation of mouse NK cell development and function by cytokines. Front Immunol (2013) 4:450. doi:10.3389/fimmu.2013.00450

34. Horng T, Bezbradica JS, Medzhitov R. NKG2D signaling is coupled to the interleukin 15 receptor signaling pathway. Nat Immunol (2007) 8:1345-52. doi:10.1038/ni1524

35. Burgess SJ, Marusina AI, Pathmanathan I, Borrego F, Coligan JE. IL-21 down-regulates NKG2D/DAP10 expression on human NK and CD8+ T cells. J Immunol (2006) 176:1490-7. doi:10.4049/jimmunol.176.3.1490

36. Takaki R, Hayakawa Y, Nelson A, Sivakumar PV, Hughes S, Smyth MJ, et al. IL-21 enhances tumor rejection through a NKG2D-dependent mechanism. J Immunol (2005) 175:2167-73. doi:10.4049/jimmunol.175.4.2167

37. Song H, Hur DY, Kim KE, Park H, Kim T, Kim CW, et al. IL-2/IL-18 prevent the down-modulation of NKG2D by TGF-beta in NK cells via the c-Jun N-terminal kinase (JNK) pathway. Cell Immunol (2006) 242:39-45. doi:10.1016/j.cellimm.2006.09.002

38. Bacon L, Eagle RA, Meyer M, Easom N, Young NT, Trowsdale J. Two human ULBP/RAET1 molecules with transmembrane regions are ligands for NKG2D. J Immunol (2004) 173:1078-84. doi:10.4049/jimmunol.173.2.1078

39. Cosman D, Mullberg J, Sutherland CL, Chin W, Armitage R, Fanslow W, et al. ULBPs, novel MHC class I-related molecules, bind to CMV glycoprotein UL16 and stimulate NK cytotoxicity through the NKG2D receptor. Immunity (2001) 14:123-33. doi:10.1016/S1074-7613(01)00095-4
40. Raulet DH, Gasser S, Gowen BG, Deng W, Jung H. Regulation of ligands for the NKG2D activating receptor. Annu Rev Immunol (2013) 31:413-41. doi:10.1146/annurev-immunol-032712-095951

41. Vetter CS, Groh V, Thor Straten P, Spies T, Brocker EB, Becker JC. Expression of stress-induced MHC class I related chain molecules on human melanoma. J Invest Dermatol (2002) 118:600-5. doi:10.1046/j.1523-1747.2002.01700.x

42. Friese MA, Platten M, Lutz SZ, Naumann U, Aulwurm S, Bischof F, et al. MICA/NKG2D-mediated immunogene therapy of experimental gliomas. Cancer Res (2003) 63:8996-9006.

43. Salih HR, Antropius H, Gieseke F, Lutz SZ, Kanz L, Rammensee HG, et al. Functional expression and release of ligands for the activating immunoreceptor NKG2D in leukemia. Blood (2003) 102:1389-96. doi:10.1182/blood-200301-0019

44. Kraetzel K, Stoelcker B, Eissner G, Multhoff G, Pfeifer M, Holler E, et al. NKG2Ddependent effector function of bronchial epithelium-activated alloreactive Tcells. Eur Respir J (2008) 32:563-70. doi:10.1183/09031936.00096407

45. Hue S, Mention JJ, Monteiro RC, Zhang S, Cellier C, Schmitz J, et al. A direct role for NKG2D/MICA interaction in villous atrophy during celiac disease. Immunity (2004) 21:367-77. doi:10.1016/j.immuni.2004.06.018

46. Allez M, Tieng V, Nakazawa A, Treton X, Pacault V, Dulphy N, et al. $\mathrm{CD} 4+\mathrm{NKG} 2 \mathrm{D}+\mathrm{T}$ cells in Crohn's disease mediate inflammatory and cytotoxic responses through MICA interactions. Gastroenterology (2007) 132:2346-58. doi:10.1053/j.gastro.2007.03.025

47. Molinero LL, Fuertes MB, Rabinovich GA, Fainboim L, Zwirner NW. Activationinduced expression of MICA on T lymphocytes involves engagement of CD3 and CD28. J Leukoc Biol (2002) 71:791-7.

48. Rabinovich BA, Li J, Shannon J, Hurren R, Chalupny J, Cosman D, et al. Activated, but not resting, T cells can be recognized and killed by syngeneic NK cells. J Immunol (2003) 170:3572-6. doi:10.4049/jimmunol.170.7.3572

49. Baragano Raneros A, Suarez-Alvarez B, Lopez-Larrea C. Secretory pathways generating immunosuppressive NKG2D ligands: new targets for therapeutic intervention. Oncoimmunology (2014) 3:e28497. doi:10.4161/onci.28497

50. Huergo-Zapico L, Acebes-Huerta A, Lopez-Soto A, Villa-Alvarez M, GonzalezRodriguez AP, Gonzalez S. Molecular bases for the regulation of NKG2D ligands in cancer. Front Immunol (2014) 5:106. doi:10.3389/fimmu.2014.00106

51. Mincheva-Nilsson L, Baranov V. Cancer exosomes and NKG2D receptorligand interactions: impairing NKG2D-mediated cytotoxicity and anti-tumour immune surveillance. Semin Cancer Biol (2014) 28:24-30. doi:10.1016/j. semcancer.2014.02.010

52. Gasser S, Orsulic S, Brown EJ, Raulet DH. The DNA damage pathway regulates innate immune system ligands of the NKG2D receptor. Nature (2005) 436:1186-90. doi:10.1038/nature03884

53. Le Bert N, Gasser S. Advances in NKG2D ligand recognition and responses by NK cells. Immunol Cell Biol (2014) 92:230-6. doi:10.1038/icb.2013.111

54. Stern-Ginossar N, Gur C, Biton M, Horwitz E, Elboim M, Stanietsky N, et al. Human microRNAs regulate stress-induced immune responses mediated by the receptor NKG2D. Nat Immunol (2008) 9:1065-73. doi:10.1038/ni.1642

55. Tokuyama M, Lorin C, Delebecque F, Jung H, Raulet DH, Coscoy L. Expression of the RAE-1 family of stimulatory NK-cell ligands requires activation of the PI3K pathway during viral infection and transformation. PLoS Pathog (2011) 7:e1002265. doi:10.1371/journal.ppat.1002265

56. Venkataraman GM, Suciu D, Groh V, Boss JM, Spies T. Promoter region architecture and transcriptional regulation of the genes for the MHC class I-related chain A and B ligands of NKG2D. J Immunol (2007) 178:961-9. doi:10.4049/jimmunol.178.2.961

57. Nice TJ, Coscoy L, Raulet DH. Posttranslational regulation of the NKG2D ligand Mult1 in response to cell stress. J Exp Med (2009) 206:287-98. doi:10.1084/jem. 20081335

58. Waldhauer I, Steinle A. Proteolytic release of soluble UL16-binding protein 2 from tumor cells. Cancer Res (2006) 66:2520-6. doi:10.1158/0008-5472.CAN05-2520

59. Clayton A, Mitchell JP, Court J, Linnane S, Mason MD, Tabi Z. Human tumorderived exosomes down-modulate NKG2D expression. J Immunol (2008) 180:7249-58. doi:10.4049/jimmunol.180.11.7249

60. Waldhauer I, Goehlsdorf D, Gieseke F, Weinschenk T, Wittenbrink M, Ludwig A, et al. Tumor-associated MICA is shed by ADAM proteases. Cancer Res (2008) 68:6368-76. doi:10.1158/0008-5472.CAN-07-6768

61. Ashiru O, Boutet P, Fernandez-Messina L, Aguera-Gonzalez S, Skepper JN, ValesGomez M, et al. Natural killer cell cytotoxicity is suppressed by exposure to the 
human NKG2D ligand $\mathrm{MICA}^{\star} 008$ that is shed by tumor cells in exosomes. Cancer Res (2010) 70:481-9. doi:10.1158/0008-5472.CAN-09-1688

62. Liu G, Atteridge CL, Wang X, Lundgren AD, Wu JD. The membrane type matrix metalloproteinase MMP14 mediates constitutive shedding of MHC class I chain-related molecule A independent of A disintegrin and metalloproteinases. J Immunol (2010) 184:3346-50. doi:10.4049/jimmunol.0903789

63. Bui JD, Carayannopoulos LN, Lanier LL, Yokoyama WM, Schreiber RD. IFNdependent down-regulation of the NKG2D ligand H60 on tumors. J Immunol (2006) 176:905-13. doi:10.4049/jimmunol.176.2.905

64. Smyth MJ, Swann J, Cretney E, Zerafa N, Yokoyama WM, Hayakawa Y. NKG2D function protects the host from tumor initiation. J Exp Med (2005) 202:583-8. doi:10.1084/jem.20050994

65. Guerra N, Tan YX, Joncker NT, Choy A, Gallardo F, Xiong N, et al. NKG2Ddeficient mice are defective in tumor surveillance in models of spontaneous malignancy. Immunity (2008) 28:571-80. doi:10.1016/j.immuni.2008.02.016

66. Liu G, Lu S, Wang X, Page ST, Higano CS, Plymate SR, et al. Perturbation of NK cell peripheral homeostasis accelerates prostate carcinoma metastasis. J Clin Invest (2013) 123:4410-22. doi:10.1172/JCI69369

67. Raffaghello L, Prigione I, Airoldi I, Camoriano M, Levreri I, Gambini C, et al. Downregulation and/or release of NKG2D ligands as immune evasion strategy of human neuroblastoma. Neoplasia (2004) 6:558-68. doi:10.1593/neo.04316

68. Coudert JD, Zimmer J, Tomasello E, Cebecauer M, Colonna M, Vivier E, et al. Altered NKG2D function in NK cells induced by chronic exposure to NKG2D ligand-expressing tumor cells. Blood (2005) 106:1711-7. doi:10.1182/blood2005-03-0918

69. Oppenheim DE, Roberts SJ, Clarke SL, Filler R, Lewis JM, Tigelaar RE, et al. Sustained localized expression of ligand for the activating NKG2D receptor impairs natural cytotoxicity in vivo and reduces tumor immunosurveillance. Nat Immunol (2005) 6:928-37. doi:10.1038/ni1239

70. Holdenrieder S, Stieber P, Peterfi A, Nagel D, Steinle A, Salih HR. Soluble MICB in malignant diseases: analysis of diagnostic significance and correlation with soluble MICA. Cancer Immunol Immunother (2006) 55:1584-9. doi:10.1007/s00262-006-0167-1

71. Holdenrieder S, Stieber P, Peterfi A, Nagel D, Steinle A, Salih HR. Soluble MICA in malignant diseases. Int J Cancer (2006) 118:684-7. doi:10.1002/ijc.21382

72. Hanaoka N, Jabri B, Dai Z, Ciszewski C, Stevens AM, Yee C, et al. NKG2D initiates caspase-mediated CD3zeta degradation and lymphocyte receptor impairments associated with human cancer and autoimmune disease. J Immunol (2010) 185:5732-42. doi:10.4049/jimmunol.1002092

73. Roberts AI, Lee L, Schwarz E, Groh V, Spies T, Ebert EC, et al. NKG2D receptors induced by IL-15 costimulate CD28-negative effector CTL in the tissue microenvironment. JImmunol (2001) 167:5527-30. doi:10.4049/jimmunol.167. 10.5527

74. Maasho K, Opoku-Anane J, Marusina AI, Coligan JE, Borrego F. NKG2D is a costimulatory receptor for human naive CD8+ T cells. J Immunol (2005) 174:4480-4. doi:10.4049/jimmunol.174.8.4480

75. Zhang C, Zhang J, Niu J, Zhang J, Tian Z. Interleukin-15 improves cytotoxicity of natural killer cells via up-regulating NKG2D and cytotoxic effector molecule expression as well as STAT1 and ERK1/2 phosphorylation. Cytokine (2008) 42:128-36. doi:10.1016/j.cyto.2008.01.003

76. Huergo-Zapico L, Acebes-Huerta A, Gonzalez-Rodriguez AP, Contesti J, Gonzalez-Garcia E, Payer AR, et al. Expansion of NK cells and reduction of
NKG2D expression in chronic lymphocytic leukemia. Correlation with progressive disease. PLoS One (2014) 9:e108326. doi:10.1371/journal.pone.0108326

77. Vuletic AM, Jovanic IP, Jurisic VB, Milovanovic ZM, Nikolic SS, Tanic NT, et al. In-vitro activation of natural killer cells from regional lymph nodes of melanoma patients with interleukin-2 and interleukin-15. Melanoma Res (2015) 25:22-34. doi:10.1097/CMR.0000000000000126

78. Cooper MA, Bush JE, Fehniger TA, Vandeusen JB, Waite RE, Liu Y, et al. In vivo evidence for a dependence on interleukin 15 for survival of natural killer cells. Blood (2002) 100:3633-8. doi:10.1182/blood-2001-12-0293

79. Ranson T, Vosshenrich CA, Corcuff E, Richard O, Muller W, Di Santo JP. IL15 is an essential mediator of peripheral NK-cell homeostasis. Blood (2003) 101:4887-93. doi:10.1182/blood-2002-11-3392

80. Boutet P, Aguera-Gonzalez S, Atkinson S, Pennington CJ, Edwards DR, Murphy G, et al. Cutting edge: the metalloproteinase ADAM17/TNF-alpha-converting enzyme regulates proteolytic shedding of the MHC class I-related chain B protein. J Immunol (2009) 182:49-53. doi:10.4049/jimmunol.182.1.49

81. Kaiser BK, Yim D, Chow IT, Gonzalez S, Dai Z, Mann HH, et al. Disulphideisomerase-enabled shedding of tumour-associated NKG2D ligands. Nature (2007) 447:482-6. doi:10.1038/nature05768

82. Wang X, Lundgren AD, Singh P, Goodlett DR, Plymate SR, Wu JD. An sixamino acid motif in the alpha3 domain of MICA is the cancer therapeutic target to inhibit shedding. Biochem Biophys Res Commun (2009) 387:476-81. doi:10.1016/j.bbrc.2009.07.062

83. Doubrovina ES, Doubrovin MM, Vider E, Sisson RB, O'reilly RJ, Dupont B, et al. Evasion from NK cell immunity by MHC class I chain-related molecules expressing colon adenocarcinoma. J Immunol (2003) 171:6891-9. doi:10.4049/ jimmunol.171.12.6891

84. Jinushi M, Hodi FS, Dranoff G. Therapy-induced antibodies to MHC class I chain-related protein A antagonize immune suppression and stimulate antitumor cytotoxicity. Proc Natl Acad Sci U S A (2006) 103:9190-5. doi:10.1073/pnas. 0603503103

85. Groh V, Li YQ, Cioca D, Hunder NN, Wang W, Riddell SR, et al. Efficient crosspriming of tumor antigen-specific $\mathrm{T}$ cells by dendritic cells sensitized with diverse anti-MICA opsonized tumor cells. Proc Natl Acad Sci U S A (2005) 102:6461-6. doi:10.1073/pnas.0501953102

Conflict of Interest Statement: The authors declare that the research was conducted in the absence of any commercial or financial relationships that could be construed as a potential conflict of interest.

Received: 23 December 2014; paper pending published: 10 February 2015; accepted: 18 February 2015; published online: 04 March 2015.

Citation: Zhang J, Basher F and Wu JD (2015) NKG2D ligands in tumor immunity: two sides of a coin. Front. Immunol. 6:97. doi: 10.3389/fimmu.2015.00097

This article was submitted to Tumor Immunity, a section of the journal Frontiers in Immunology.

Copyright (c) 2015 Zhang, Basher and Wu. This is an open-access article distributed under the terms of the Creative Commons Attribution License (CC BY). The use, distribution or reproduction in other forums is permitted, provided the original author(s) or licensor are credited and that the original publication in this journal is cited, in accordance with accepted academic practice. No use, distribution or reproduction is permitted which does not comply with these terms. 